\title{
Medicina defensiva: uma prática necessária?
}

\section{Defensive medicine: a necessary practice?}

\author{
José Guilherme Minossı,TCBC-SP¹; Alcino LaZARo da Silva, ECBC-MG²
}

\author{
RE S U M O
}

\begin{abstract}
O artigo em questão aborda os motivos pelos quais a Medicina Defensiva é largamente utilizada no Brasil e no Mundo. A Medicina Defensiva, na prática, se caracteriza pela utilização exagerada de exames complementares, pelo uso de procedimentos terapêuticos supostamente mais seguros, pelo encaminhamento frequente de pacientes a outros especialistas e pela recusa ao atendimento de pacientes graves e com maior potencial de complicações. Trata-se de uma prática que tem como objetivo principal defender 0 médico de eventuais processos, principalmente na área judicial. A maneira como são conduzidos os processos pelo poder judiciário certamente contribui para a consolidação desta prática insensata. A morosidade da justiça, em nosso meio, associado ao despreparo dos juízes e peritos judiciais na análise dos casos, leva a um desgaste emocional das partes. Alem disso, a formação precária do médico em nosso país faz com que se utilize de meios requintados de diagnóstico e tratamento em detrimento a um exame clínico pormenorizado e uma adequada comunicação com o paciente. Além de ineficiente em proteger o médico, a Medicina Defensiva traz consequências graves ao paciente e à sociedade, já que gera um custo adicional incalculável ao exercício da Medicina, determina um maior sofrimento ao doente e faz com que haja uma deteriorização na relação médico-paciente, que sempre foi pautada pela confiança, respeito e pessoalidade.
\end{abstract}

Descritores: Medicina defensiva. Procedimentos clínicos. Prática profissional. Erros médicos. Prova pericial.

\section{INTRODUÇÃO}

A "Medicina Defensiva" defensiva surgiu na década de 90 nos Estados Unidos da América, numa tentativa de fazer frente às crescentes demandas legais dos pacientes. Ela pode ser definida como uma prática médica que prioriza condutas e estratégias diagnósticas e/ou terapêuticas e que têm como objetivo evitar demandas nos tribunais.

Embora o médico possa ser acionado nos tribunais de ética e do Poder Judiciário, é neste último que há o maior temor, particularmente com relação aos processos na justiça civil, em que a condenação visa à reparação de um dano ao paciente e tem caráter indenizatório por danos materiais e morais.

Um estudo do Reino Unido (1995) mostrou que a maioria dos médicos $(63,8 \%)$ realizava práticas defensivas como: encaminhar pacientes desnecessariamente para outros médicos, realizar exames de controles não indicados em mais da metade das vezes $(63,4 \%)$ e solicitar exames complementares não justificados em 59,6\% dos ca$\operatorname{sos}^{1}$.

Um estudo no México mostrou que $61 \%$ dos médicos utilizam práticas defensivas ${ }^{2,3}$. Estimativas realizadas nos Estados Unidos no ano de 1995 mostraram que $17,6 \%$ dos gastos da atenção médica se referiam às práticas de medicina defensiva. Para cada dólar destinado a cobrir as apólices de seguros de responsabilidade profissional, U\$ $\$ 2,70$ dólares se destinavam ao produto de práticas defensivas ${ }^{4,5}$. O temor às demandas gerou gastos superiores a 10 bilhões de dólares somente nos Estados Unidos, por meio da medicina defensiva.

Mais de $90 \%$ dos médicos entrevistados pela Escola de Saúde Pública de Harvard praticam a chamada "medicina defensiva", que inclui exames caros e tem o objetivo de evitar possíveis processos.

No Brasil, embora sem estudos específicos sobre o assunto, podemos observar na prática médica diária a consolidação da medicina defensiva. Embora exista em nosso meio cada vez mais o temor de processos contra médicos, certamente esta prática defensiva ocorre também em decorrência da precária formação médica em nosso país, fazendo com que o profissional recém-ingressado no mercado de trabalho utilize meios requintados de diagnósticos em detrimento ao exame clínico pormenorizado e de uma adequada comunicação com o paciente.

A formação precária do profissional decorre do fato de que em nosso país há um grande número de escolas médicas, com cursos de graduação, de um modo geral, deficitários, sendo que quase $50 \%$ dos formados não têm acesso a uma residência médica ou a um curso de especialização.

1. Professor Doutor do Departamento de Cirurgia e Ortopedia da Faculdade de Medicina de Botucatu - UNESP-SP-BR; 2. Professor Emérito da Universidade Federal de Minas Gerais: UFMG. 
Além das péssimas condições de ensino e aprendizagem, temos os baixos salários dos professores e dos próprios médicos, falta de recursos para a pesquisa e extensão, e condições inadequadas de trabalho.

A medicina defensiva, na prática, se caracteriza pela utilização exagerada de exames complementares, uso de procedimentos terapêuticos supostamente mais seguros, encaminhamento freqüente de pacientes a outros especialistas e a recusa ao atendimento de pacientes graves e com maior potencial de complicações.

Exames complementares são realizados de forma abusiva pelos profissionais, na tentativa de evitar possíveis acusações de negligência ou omissão em caso de insucesso. Isto pode ser exemplificado pelo uso rotineiro de exames pré-operatórios em demasia para todos os pacientes que serão submetidos a uma operação, independente da idade e complexidade do procedimento. Sabemos muito bem que uma avaliação clínica criteriosa pode dispensar exames em pacientes abaixo de 40 anos de idade. Acima desta faixa etária os exames devem ser solicitados criteriosamente, sendo dispensáveis, de um modo geral, as dosagens de eletrólitos, enzimas hepáticas, avaliação cardiológica e pulmonar, que somente deve ser usada quando o exame clínico indicar alguma anormalidade específica nesses aparelhos, ou o paciente apresentar doenças prévias.

A maior parte dos pacientes portadores de cefaleia não precisa de uma tomografia computadorizada ou uma ressonância magnética como reza um manual de medicina defensiva ${ }^{6}$. Precisa sim de uma história clínica e um exame físico bem realizado. Da mesma maneira tornou-se rotina o uso da tomografia computadorizada ou da ressonância magnética em casos de traumatismo de crânio, por menor que seja, independente de sua natureza ou da sintomatologia.

Temos observado na prática clínica diária que pacientes com queixas vagas de refluxo, dispepsia, alteração do hábito intestinal, normalmente por síndrome do intestino irritável, são submetidos a um número exagerado de endoscopias digestivas altas e colonoscopias, exames que eventualmente podem terminar em complicações graves. Esta prática não tem somente finalidade defensiva, mas por vezes visa à criação de um procedimento médico com intuito de aumentar a remuneração do facultativo, situação ainda mais grave e odiosa que a própria prática defensiva.

Um inquérito realizado pelo Colégio Americano de Cirurgiões, entre 16.000 de seus membros, revelou que cerca de metade dos exames solicitados eram reconhecidamente dispensáveis, porém, foram realizados como autoproteção do médico contra possíveis processos de máprática.

Não resta dúvida de que o uso criterioso de exames nas situações descritas é uma prática mais racional e traz melhores custos e benefícios.
Nos poucos casos em que a não realização de um exame pré-operatório para fins diagnósticos mostrar-se posteriormente importante, não pode ser considerado que o médico foi negligente ou omisso, desde que o mesmo tenha realizado uma propedêutica adequada, anotado em prontuário e inclusive colocado uma observação de que o caso deveria ser reavaliado em breve. Exemplificando: um paciente relativamente jovem que foi orientado sobre um quadro de dispepsia e que em decorrência da não melhora, realizou um exame complementar num período curto de tempo sendo neste revelado um tumor de colon, certamente não deve ser imputada ao médico uma culpa. Da mesma forma, o médico que ao indicar mal uma colonoscopia e tem como complicação uma perfuração colônica deve ser considerado imprudente, pois o resultado não foi apenas indesejável e sim decorrente de um ato culposo.

Podemos observar também o uso exagerado de exames na área da cardiologia. Certamente, a maior parte dos pacientes que procuram o cardiologista poderiam resolver seus problemas com uma simples consulta médica e orientação. O que se observa, no entanto, é que frequentemente a realização de um eletrocardiograma precede inclusive o exame clínico. Da mesma forma são usados indiscriminadamente exames mais requintados, como monitoramentos de 24 horas, ecocardiograma, cintilografia, angiotomografia, cateterismo, etc. Percebe-se então que não há a preocupação em estabelecer um diagnóstico, mas, simplesmente excluir doenças.

Com relação ao uso de procedimentos terapêuticos como prática defensiva, podemos citar o uso exagerado de antibióticos preventivos em operações, que por vezes não seguem uma indicação adequada ou são utilizados por períodos prolongados. Recentemente em um congresso de cirurgia o conferencista foi indagado do porquê de se utilizar rotineiramente antibióticos preventivos nas hemorroidectomias. E a reposta foi de que era para se proteger de possíveis conflitos médico-legais, caso o paciente tivesse uma infecção. A maioria dos serviços de cirurgia não utiliza antibiótico profilático em doenças orificiais tratadas cirurgicamente, devido ao baixo índice de infecção pós-operatória. A infecção é uma complicação inexorável e pode ocorrer após qualquer tipo de operação. Caso aconteça, o médico tem todos os meios de executar sua defesa com segurança.

Em cirurgia geral temos ainda observado um fato inusitado com relação à correção das hérnias inguinais. Os americanos estabeleceram que o padrão-ouro na correção deste defeito é através da utilização de próteses.

A utilização desses biomateriais de fato faz com que a recidiva das hérnias seja muito baixa, em torno de $1 \%$. Todavia o índice de complicações com a utilização dessas próteses chega a níveis preocupantes, principalmente a extrusão (2\%), inguinodinia (10\%), dentre outras. Entendemos que o uso sistemático das telas se constitui em um abuso ${ }^{7}$, embora tenha amplas indicações. Certamente 
o uso racional das próteses, baseando-se nos defeitos anátomo-funcionais da região inguinal seria uma conduta mais prudente ${ }^{8}$. É possível que a busca por uma recidiva próxima a zero, seja pelo temor em enfrentar este tipo de complicação e suas conseqüências legais.

Este fato criou uma situação paradoxal, pois pode deixar desprotegido aquele médico que eventualmente não faz uso do material, de modo rotineiro, por não julgá-lo necessário, e o paciente apresenta uma recidiva.

Na prática cirúrgica diária devemos sempre considerar qual o melhor método se aplica àquele caso e não tratar a recidiva ou mesmo outras complicações como um insucesso decorrente de um ato culposo do cirurgião, desde que o mesmo tenha respeitado todos seus deveres de conduta.

Com relação ao encaminhamento de pacientes a outros especialistas, tem-se observado que esta é uma prática defensiva comum, principalmente entre os médicos do SUS e os que atendem convênios. De um modo geral não querem se compromissar a ver o paciente como um todo e solicitam avaliação especializada frente a qualquer queixa que não a de sua área de atuação. Este fato além de aumentar os gastos com a saúde, faz aumentar as filas e diminui a resolução dos casos. Não há dúvidas de que a baixa remuneração do profissional é outro fator que favorece esta conduta.

A recusa de pacientes se constitui também em uma prática defensiva comum que pode acarretar graves complicações ao doente.

No manual de medicina defensiva há conselhos para o médico evitar o paciente de risco, dentre eles os pacientes que recusam determinadas terapias por razões éticas ou religiosas, como os seguidores da religião "Testemunhas de Jeová". Recentemente o anestesista de nosso serviço suspendeu a cirurgia de correção de cistocele e retocele de um paciente da referida religião. Trata-se de uma conduta inaceitável, pois é um desrespeito a autonomia do paciente. Sem dizer que o procedimento é de baixíssima possibilidade de transfusão. É um caso nítido de medicina defensiva e confronto desnecessário para com o paciente. Se todos os médicos fizerem isso, quem vai atender esses doentes? O médico deve ter respeito profundo à diversidade religiosa, à opção sexual ou política. Isto é característica da sociedade democrática e uma das grandes responsabilidades do médico.

A recusa de pacientes também ocorre em situações em que há grande risco de complicações, como em algumas operações neurológicas, cardiovasculares e transplantes.

No Brasil, muitas vezes a recusa acontece também devido aos baixos valores pagos pelos procedimentos, tanto no SUS, como nos convênios, o que faz com que o médico atue na defensiva, pois se tiver um mal resultado e um conflito médico-legal, os gastos com a condução do processo são elevados, sem falar no desgaste emocional e no tempo longo de tramitação da ação.

\section{A MEDICINA DEFENSIVA COMO SUPOSTA MEDIDA DE PROTEÇÃO CONTRA PROCESSOS LEGAIS}

A legislação brasileira é bastante justa em seu ordenamento jurídico no que se refere à responsabilidade penal e civil do médico. Da mesma maneira o é o código de Ética Médica, aplicado pelos tribunais de Ética, dos Conselhos Regionais e Federal de Medicina.

O médico para ser condenado por qualquer um dos tribunais, principalmente na justiça civil, em que acontece a maioria das ações por responsabilidade médica, precisa provocar um dano ao seu paciente, e este dano tem que ser o resultado de um ato culposo, isto é, tem que agir com imperícia, negligência ou imprudência.

Por maior que seja o dano, o médico só será condenado, se houver culpa. A medicina atual, detentora de um grande avanço tecnológico, beneficiando muito o paciente, tornou-se mais invasiva, com maiores riscos de danos ao paciente.

Sendo assim a proteção do médico não pode ser realizada através da medicina defensiva, que se constitui em um fator de diminuição da assistência aos pacientes de maior risco, leva a um maior custo da medicina, não só para o usuário, como também para a sociedade como um todo?.

As medidas de proteção incluem, além da aplicação cautelosa dos novos avanços tecnológicos, uma relação médico paciente mais pessoal e o conhecimento dos deveres de conduta do médico, já que toda vez que se avalia a responsabilidade de um profissional em determinado ato médico, tanto no âmbito ético ou legal, leva-se em consideração esses deveres de conduta, que resumidamente são:

- Dever de informação: é fundamental que o paciente seja informado pelo médico sobre a necessidade de determinadas condutas ou intervenções e sobre seus riscos e conseqüências. No caso de menores ou incapazes, essas informações devem ser fornecidas aos pais ou representante legal.

É necessário que todas as informações sejam registradas no prontuário, que é uma das primeiras fontes de consulta e informação sobre um procedimento médico contestado.

- Dever de atualização: o regular exercício profissional do médico não requer apenas uma habilitação legal. Implica também no aprimoramento contínuo, adquirido por meio dos conhecimentos mais recentes da nossa profissão. A capacitação profissional é sempre verificada toda vez que se discute uma responsabilidade médica. Além disso, o artigo 5, do Código de Ética Médica, diz que: "o médico deve aprimorar continuamente seus conhecimentos e usar o melhor do progresso científico em benefício do paciente".

- Dever de vigilância: o ato médico deve ser isento de qualquer tipo de omissão que possa ser caracteri- 
zado por inércia, passividade ou descaso. Essa omissão tanto pode ser por abandono do paciente, como por restrição do tratamento ou retardo no encaminhamento necessário.

Enquadra-se nessa situação, a troca de medicamento por letra indecifrável, o esquecimento de corpo estranho em operações, medicar por telefone, transfusões incompatíveis, dentre outras.

- Dever de abstenção de abuso: quando da avaliação do dano produzido por um ato médico, deve ficar claro, entre outros, se o profissional agiu com cautela devida e, portanto, descaracterizado de precipitação, inoportunismo ou insensatez.

Exceder-se na terapêutica ou nos meios propedêuticos mais arriscados é uma forma de desvio de poder e, se o dano deveu-se a isso, não há como negar a responsabilidade. Ainda que esses meios não sejam invasivos ou de grande porte, basta ficar patente a sua desnecessidade.

Sendo assim, usar abusivamente de meios diagnósticos invasivos ou não, indicar operações desnecessárias, realizar experiências no ser humano, fora de protocolos de estudo e sem o devido consentimento, são algumas formas de abuso que por vezes terminam em dano ao paciente e, portanto, são passíveis de condenação do médico.

Além de conhecer com precisão os deveres de conduta, uma maneira de se prevenir os erros no exercício da medicina, é conhecer os fatores de risco. Na prática são muitos os fatores de risco que levam ao mau resultado e são classificados didaticamente em assistenciais e não assistenciais ${ }^{9,10}$.

Entre os fatores de risco não assistenciais, destacam-se:

\section{1) O Sistema de Saúde}

O Sistema de Saúde Pública é distorcido e desorganizado. Temos uma rede básica de saúde que funciona mal, é desestruturada na maioria dos municípios brasileiros, onde existem profissionais mal remunerados, com limitação de sua atuação. Consequentemente, a população não consegue ter uma resolutividade adequada dos problemas que a afligem.

A rede hospitalar de quase todo país, onde deveria se exercer a Medicina Curativa e de Urgência, está cada vez mais sucateada, haja vista os insuficientes investimentos tanto pelo poder público municipal e estadual, bem como federal. Todavia, existem ilhas de serviços públicos eficientes, normalmente concentrados em grandes hospitais públicos ou fundações, ou em centros universitários de excelência, que frequentemente executam procedimentos de alta complexidade.

Por outro lado, a criação das empresas de assistência médica que prioritariamente visam ao lucro, além de remunerarem mal os profissionais da saúde, com frequência, limita a sua atuação, o que coloca entre o médico e os pacientes muitos conflitos, os quais, quase sempre levam a complexas implicações de ordem ética e legal.
Portanto, o médico exerce suas atividades em um ambiente de penúria e precariedade.

\section{2) A falta de compromisso do médico}

O médico deve trabalhar sempre em condições próximas às ideais, devendo denunciar as condições inadequadas de trabalho, não ficando indiferente como tem acontecido, pois o exercício da Medicina é um ato político em favor da saúde individual e coletiva, e também a busca da cidadania. É dever de o médico lutar organizadamente em favor das melhores condições de atendimento e não considerar a doença como um resultado da fatalidade.

\section{3) A falta de participação da sociedade}

A sociedade, por intermédio dos seus movimentos organizados, deve entender que a luta contra o mau resultado na assistência médica passa por propostas e encaminhamentos das políticas sociais, públicas e que esse resultado indesejável não tem como única causa os erros dos médicos. Sendo assim, o ideal seria que esses grupos se aliassem aos médicos e a todos aqueles que se interessam pela luta em favor da boa assistência médica, no sentido de exigir, principalmente, de órgãos governamentais, uma melhoria nas condições de vida e saúde da população.

\section{4) A ausência de revisão do aparelho for-}

\section{mador}

O Brasil é o país que tem o maior número de escolas médicas do mundo, com cursos de graduação, de um modo geral, deficitários, sendo que quase $50 \%$ dos formandos não têm acesso a uma residência médica ou a um curso de especialização.

Além das péssimas condições de ensino e aprendizagem, temos os baixos salários dos professores e o aparelho formador não lança no mercado de trabalho médicos com o perfil adequado para as exigências da sociedade. Sem falar, ainda, na falta de recursos para a pesquisa e a extensão.

Seria necessária uma revisão sobre a qualidade de ensino, e também dos critérios adotados para abertura de novos cursos de Medicina.

\section{5) A falta de ensino contínuo}

É evidente que para se exercer a profissão médica não basta apenas uma habilitação legal, representada pela posse de um diploma e seu registro nos Conselhos de Medicina. É necessária uma contínua habilitação profissional constituída de um permanente aprendizado, que pode ser adquirido por meio da leitura das publicações especializadas, participação em congressos, curso de especialização ou estágios em centros hospitalares de referência.

Com relação aos fatores assistenciais podemos citar:

1) $O$ desgaste da relação médico-paciente

Uma relação médico-paciente amistosa deixa o assistente e o assistido em condições de exercer 
com tranquilidade seus papeis. O que se observa é um desgaste dessa relação, por inúmeros motivos, dentre os quais: o pequeno tempo que o médico tem dedicado a conversar com o paciente, principalmente, por ser mal remunerado, por ter vários empregos e também pelo uso excessivo da tecnologia em detrimento da medicina tradicional, baseada na observação, na história, na percepção da doença e do doente. Deve o médico encontrar uma maneira de dedicar maior tempo ao contato com o paciente, orientando-o de forma mais carinhosa e explicando-lhe sobre todos os procedimentos a serem realizados, com seus riscos e consequências. Mesma conduta deve ser adotada em relação aos familiares, pois um relacionamento mais pessoal com o assistido e seus próximos podem evitar muitos conflitos legais.

\section{2) A falta de condições de trabalho}

Não há nenhuma dúvida de que boa parte dos danos produzidos no exercício da Medicina se deve às péssimas condições de trabalho dos médicos. Mais fácil porém é culpar os mesmos como os primeiros responsáveis. Pouco pode ser feito pelo profissional isoladamente, que na maioria das vezes não tem outra opção a não ser submeter-se a condições precárias e humilhantes do seu dia a dia de trabaIho. Nossas entidades de classe, inexplicavelmente, têm tido pouco poder de denunciar e tentar resolver junto aos órgãos municipais, estaduais e federais essas graves falhas estruturais de nosso sistema de saúde.

\section{3) O abuso de poder}

Abusa do poder o médico que atua sem a devida cautela, isto é, de maneira precipitada, inoportuna ou insensata. Uma forma comum de desvio do poder é o médico que executa procedimentos sem ter a devida qualificação. Isso não significa que o médico deva exercer exclusivamente sua especialidade. Pode e deve atuar em diversas áreas da Medicina, sempre em benefício do paciente, mas essa atuação deve ser prudente, diligente e com perícia.

\section{4) A falsa garantia de resultado}

O médico, embora deva ser sempre otimista quando se relaciona com o paciente, ele não deve garantir resultados, pois caso o faça, ele está assumindo uma obrigação de resultados. Deve evitar, também, minimizar um procedimento, como por exemplo, na cirurgia laparoscópica, em que alguns profissionais se comprometem a realizar a intervenção por "furinhos" ou a "laser", como é chamada popularmente a cirurgia por laparoscopia. Caso o resultado não seja obtido, passa a ser uma violação ao dever de informar, devida e corretamente.

5) A falta de consentimento esclarecido

Trata-se de documento assinado pelo paciente ou responsável, consentindo ao médico a realização de determinado procedimento diagnóstico ou terapêutico, após haver recebido informações indispensáveis sobre a sua execução.

O consentimento deve ser obtido de um indivíduo civilmente capaz, isento de coação, influência ou indução, por meio de linguagem acessível ao seu nível de conhecimento e compreensão. O consentimento não é um ato irretratável e permanente, portanto, deve obedecer aos princípios da revogabilidade e da temporalidade.

O termo de consentimento esclarecido deve ser encarado como uma peça para a defesa do médico, não se constituindo, todavia, em prova absoluta, pois apenas integra, na qualidade de prova documental, o arsenal probatório a ser apresentado ao juízo.

Por outro lado, deve ficar claro que o fato de se ter um consentimento esclarecido, isto, por si só, não isenta o médico quando da existência de outras faltas no cumprimento dos deveres de conduta.

\section{tuários}

\section{6) 0 preenchimento inadequado de pron-}

Um dos elementos mais valorizados quando da avaliação de um procedimento médico contestado é o prontuário do paciente.

O prontuário deve ser minucioso, estar de forma legível, ordenado e conciso. Deve conter o exame clínico, prescrição, relatórios de enfermagem, os relatórios de anestesia, operação, a ficha de registro de resultados de exames complementares, além da ficha de controle de infecção e resumo de alta.

Apesar da importância deste documento, temse observado nos casos de perícias judiciais que muitas vezes o mesmo é incompleto, com letra ilegível, com dados conflitantes com a enfermagem, quando eventualmente ausente.

\section{7) 0 abandono do paciente}

A regra é que o médico não pode abandonar seu paciente, a não ser em situações muito especiais, previstas no artigo 61 do Código de Ética Médica, já que existe entre o médico e o paciente uma relação contratual.

Falta com o dever de vigilância em casos de operação o médico que negligencia algumas complicações pós-operatórias, como por exemplo, os cuidados com a hidratação, o diagnóstico precoce de deiscência de suturas, infecções, etc, que normalmente requerem uma conduta imediata.

\section{O USO DO CONSENTIMENTO INFORMADO E A MEDICINA DEFENSIVA}

Existem, no momento, duas concepções distintas sobre o consentimento informado ${ }^{11}$. Em uma delas, que tem a medicina defensiva como referencial, se entende 
que o termo de consentimento informado é um instrumento documental, que deve ser assinado pelo paciente e que tem como objetivo constituir provas para uma futura defesa de um eventual processo judicial de responsabilidade médica. Já na outra concepção, fundada na bioética, percebe-se o consentimento informado como um processo contínuo de informação e esclarecimento recíproco nas relações entre prestadores e usuários de serviços de saúde, visando a proteger prioritariamente a autodeterminação do paciente.

$\mathrm{Na}$ verdade o consentimento informado deve ser tratado como um documento assinado pelo paciente ou responsável, consentindo ao médico a realização de determinado procedimento diagnóstico ou terapêutico, após haver informações indispensáveis sobre a sua execução. Tem como finalidade garantir a autonomia do paciente e delimitar a responsabilidade do médico que realiza o procedimento, uma vez que desta forma cumpre com o seu dever de bem informar. ${ }^{10}$

Um paciente, por exemplo, que por motivos religiosos, não aceita transfusão de sangue durante uma operação, tem a sua vontade e autonomia expressa neste documento e o médico sua responsabilidade delimitada. No caso de um paciente que vai ser submetido a uma colecistectomia videolaparoscópica e é informado sobre as possibilidades de conversão para cirurgia aberta, assim como possibilidade de lesões iatrogênicas das vias biliares. Frente a uma dessas intercorrências não pode alegar desconhecimento, desde que adequadamente informado.

Um doente que vai ser submetido a uma herniorrafia inguinal deve ser orientado não só quanto à possibilidade de recidiva, como também quanto às eventuais complicações tardias do uso das próteses. ${ }^{12}$

Entendemos que se essas informações forem adequadamente registradas em prontuário, têm valor ético e legal semelhante ao termo de consentimento. Isto porque o termo de consentimento informado não consegue prever todas as possibilidades de intercorrências ou complicações em um determinado caso.

O termo de consentimento informado não deve ser usado também como substitutivo da comunicação oral, podendo assim, ao contrário de seu objetivo, gerar desconfiança em relação aos médicos e aumentar a potencialidade de conflitos. ${ }^{13} \mathrm{~A}$ informação escrita pode ajudar o diálogo, mas não o substitui. ${ }^{14}$

Embora o consentimento informado seja uma exigência ética e jurídica na assistência médica atual, entende-se que não é necessário e nem aconselhável obter a assinatura do paciente em documentos escritos de consentimento informado para todo e qualquer procedimento, numa clara prática de medicina defensiva. Não há garantia de que esta conduta irá evitar futuras demandas judiciais, além de, com isso, criar-se um distanciamento e desconfiança na relação médico-paciente.

Da mesma forma, deve-se evitar exageros na elaboração do documento,uma vez que pode assustar o paciente e dificultar seu acesso ao tratamento. Se fizermos um jovem que será submetido a uma herniorrafia inguinal, assinar um documento onde consta que após o procedimento, o mesmo poderá perder um testículo, certamente irá recusar-se a submeter-se ao tratamento cirúrgico e poderá ter as complicações de sua doença posteriormente.

É recomendável que os médicos mantenham sempre adequadamente elaborados os prontuários dos pacientes, incluindo o registro das informações que foram transmitidas e o grau de participação dos pacientes e seus familiares nas decisões terapêuticas. Tais documentos, caso sejam devidamente preenchidos, podem servir como prova de que foi cumprido o dever de informar, que é conteúdo do consentimento informado. Também servem para registrar o grau de comprometimento e cooperação dos pacientes, o que é imprescindível para a eficácia dos serviços médicos.

\section{CONSEQUENCIAS DA MEDICINA DEFENSIVA}

As conseqüências mais evidentes desta prática médica são:

1. Onerar excessivamente o paciente

2. Onerar excessivamente os planos de saúde

3. Interferir negativamente na relação amistosa que o médico deve ter com seus pacientes e familiares

4. Recusa no atendimento a pacientes graves, com doenças complexas e com potencial de complicações ou seqüelas

5. Maior sofrimento ao paciente

O maior sofrimento ao paciente não decorre apenas do fato de a medicina tornar-se mais dispendiosa e artificial, mas também da menor resolutividade. Encaminha-se demais, realizam-se exames excessivamente, quando poderia ser dada uma solução de maneira mais simples e efetiva à maioria dos males que aflige a população. A recusa de pacientes graves é outro fator que gera sofrimento, pois a não realização de um tratamento por vezes efetivo, deixa o paciente à própria sorte.

\section{CONSIDERAÇÕES FINAIS}

A Medicina defensiva é uma prática médica largamente utilizada em nosso meio e em muitos países do mundo.

O objetivo principal desta conduta equivocada seria defender o médico de eventuais processos, principalmente os judiciais e o aumento de processos contra médicos, observados nos últimos anos, fez com que esta prática ganhasse terreno.

Certamente um aspecto que gera tensão e medo no profissional médico é a maneira como são conduzidos os processos na justiça. Além da morosidade da justiça, em nosso meio, que sem dúvida leva a um desgaste emocional às partes envolvidas, temos observado na prática o 
despreparo dos juízes e também dos peritos judiciais, na análise dos casos, fato que pode com certeza fazer com que a verdadeira justiça não seja feita, prejudicando uma das partes.

No tribunal se tem dado muita importância à farta documentação existente nos autos. Desconsidera-se de um modo geral a prática médica mais simples, baseada na história, observação clínica e larga e sedimentada experiência profissional.

O julgador tem que conhecer a complexidade em que se situa hoje a ciência médica e entender que o médico, basicamente, erra quando não cumpre com seus deveres de conduta. Daí a importância do julgador em participar ativamente do processo e não apenas observar o embate entre as partes.

Por outro lado, o perito judicial deve ter não só conhecimentos amplos de medicina como também entender todos os processos que envolvem o erro médico e o mau resultado.

\section{CONCLUSÃO}

A Medicina Defensiva é um desvio da prática médica sensata, induzido, principalmente, pela ameaça de processos por negligência profissional.

Além de ineficiente em proteger o médico, ela traz conseqüências graves ao paciente e à sociedade, já que gera um custo adicional incalculável ao exercício da medicina, determina um maior sofrimento ao doente e faz com que haja uma deteriorização na relação médico-paciente, que sempre foi pautada pela confiança, respeito e pessoalidade.

A maneira mais efetiva para se evitar os conflitos entre o médico e seu paciente, certamente, não passa pela utilização desta prática médica, mas sim pelo cultivo de uma boa relação médico-paciente-familiar, pelo conhecimento dos deveres de conduta do médico, evitando assim a possibilidade de cometer erros.

Por fim recomenda-se que os prontuários dos pacientes sejam sempre adequadamente elaborados, incluindo o registro das informações que foram transmitidas e o grau de participação dos pacientes e seus familiares nas decisões terapêuticas. Tais documentos, caso sejam devidamente preenchidos, podem servir como prova de que foi cumprido um dos deveres de conduta médica, que é o dever de informação, e, certamente, provar que o médico atuou com todo zelo e cuidado, que deve ser pautado o exercício desta nobre profissão.

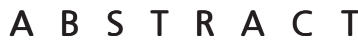

We discuss the reasons why Defensive Medicine is widely used in Brazil and worldwide. The Defensive Medicine is characterized by excessive use of complementary tests, the use of supposedly safer therapeutic procedures, the frequent referral of patients to other specialists and by the refusal to care for critically ill patients and with greater potential for complications. This is a practice that aims to defend the doctor from legal suits. The way the processes are conducted by the judiciary certainly contributes to the consolidation of this foolish practice. The slow pace of justice in our country, associated with the unpreparedness of judges and legal experts in the analysis of cases, leads to an emotional exhaustion of the parties involved. Furthermore, poor training of doctors in our country values the use of sophisticated diagnostic and treatment methods, rather than a thorough clinical examination and appropriate communication with the patient. Besides inefficient in protecting the doctor, Defensive Medicine has severe consequences to the patient and to society, since it generates an additional invaluable cost to medical practice, determines greater suffering to the patient and causes deterioration of the doctor-patient relationship, which has always been marked by trust, respect and personhood.

Key words: Defensive medicine. Critical care. Professional practice. Medical errors. Expert testiony.

\section{REFERÊNCIAS}

1. Rodríguez Almada H. De la medicina defensiva e la medicina asertiva. Rev méd Urug. 2006;22(3):167-8.

2. Sánches-Gonzáles JM, Tena-Tamayo C, Campos-Castolo EM, Hernández-Gamboa LE, Rivera-Cisneros AE. Medicina defensiva en México: una encuesta exploratoria para su caracterización. Cir Cir. 2005;73(3):199-206.

3. Summerton N, Graham JR. Effects of the medical liability system in Austrália, the UK, and the USA. Lancet. 2006;368:240-6.

4. Reynold S, Rizzo JA, Gonzalez ML. The cost of medical professional liability. Jama. 1987;257(20):2776-81.

5. Tena-Tamayo C, Sanches-Gonzalez JM. Medicina asertiva. Una alternativa para mejorar la calidad. In: Tena-Tamayo C. HernandezOrozeo F. La comunicacion humana em la relacion medico-paciente. Mexico: Prado; 2005. p.407-27.

6. Ilano E. Medicina defensiva: em defesa de quem? Ser médico. Revista do Cremesp, Ed.21. Dezembro, 2002.
7. Minossi JG, Silva AL, Spadella CT. O uso da prótese na correção das hérnias da parede abdominal. É um avanço, mas o seu uso indiscriminado, um abuso. Rev Col Bras Cir. 2008;35(6):418-23.

8. Minossi JG, Kemp R, Picanço HC, Spadella CT. Avaliação pósoperatória tardia de pacientes submetidos à herniorrafia inguinocrural por via anterior, utilizando a técnica convencional ou a colocação de prótese sintética. $A B C D$ arq bras cir dig. 2004;17(4):163-9.

9. Minossi JG. Prevenção de conflitos médico legais no exercício da medicina. Rev Col Bras Cir. 2009:36(1):90-5.

10. Veloso de França G. Direito médico. 8a ed. São Paulo: BYK; 2003.

11. Pithan JH. O consentimento informado para além da medicina defensiva. Rev AMRIGS. 2009;53(2):175-8.

12. Minossi JG, Silva AL. Aspectos médico-legais da cirurgia para hérnia inguinal. Rev Col Bras Cir. 2005;32(4):214-7.

13. Lown B. A arte perdida de curar. São Paulo: ISN; 1997. p.162.

14. Pereira ACD. O consentimento informado na relação médicopaciente: estudo de direito civil. Coimbra: Coimbra; 2004. p.536. 
Recebido em 10/12/2012

Aceito para publicação em 15/05/2012

\section{Como citar este artigo:}

Minossi JG, Silva AL. Medicina defensiva: uma prática necessária? Rev

Col Bras Cir. [periódico na Internet] 2013;40(6). Disponível em URL: http://www.scielo.br/rcbc
Endereço para correspondência:

José Guilherme Minossi

E-mail: jminossi@uol.com.br 